\title{
The short-term health promotion effect of the whole-body vibration exercise program for the improvement of the agility, the quick reaction ability, and the flexibility of the students aspiring for the physical education-affiliated departments in Korea
}

\author{
Joon-Hee Kim* \\ Department of Sports \& Outdoors, College of Health Industry, Eulji University, Seongnam, Korea
}

The present study aimed to comparatively analyze the effects of the whole-body vibration exercise health promotion program on the agility, the quick reaction ability, and the flexibility of the test-takers. Total 30 test-takers had been prepared for the practical test as the subjects. They were divided into the three groups: the practical college entrance examination group with whole-body vibration exercise, the practical college entrance examination group, and the control group. The measurements of each item were made before and after the program applications of the side steps, the standing long jump, the standing high jump, the sitting trunk flexion, and the trunk forward flexion for 60 min 3 times a week. The side steps showed the significant differences among the groups. Although the standing long jump did not show any significant differences among the groups, the standing high jump showed the significant differences among the groups. Although the sit- ting trunk flexion showed the significant differences among the groups, the trunk forward flexion did not show any significant differences among the groups. But, the practical college entrance examination program group which carried out the whole-body vibration exercise at the same time showed the highest average value compared to the other groups. It was proven that, to the test-takers who had been preparing for the preparing examination for applying to a physical education-affiliated department, the whole-body vibration exercise program is helpful to the promotion of the health, including the agility, the quick reaction ability, the flexibility, etc.

Keywords: Stroke, Whole-body vibration, Agility, Quickness, Flexibility, Health promotion

\section{INTRODUCTION}

If we take a look at the present situation of the applications to the physical education colleges of Korea, the trend of the increase of the number of the students applying for the college entrance examination has been continuing, including 36,884 people in the year 2005, 58,523 people in the year 2013, and 68,611 people in the year 2017. The students who are applying to a Korean physical education college are largely divided into the special selection who are applying with the career experience of having won the awards as an athlete and the general selection who are applying through the practical examination. Most of the students get around to applying through the general selection. Because, regarding the general selection, the ratio of the reflection of the practical capability is high, the students who are applying through this have been preparing for the relevant, practical examination through an ordinary, private, educational institution. And they have been consuming around $3 \mathrm{hr}$ each for around 3 times per 1 ordinary week. Because, regarding the practical capability for going on to a school at a physical education college, mainly,
*Corresponding author: Joon-Hee Kim (D) https://orcid.org/0000-0001-7231-9481 Department of Sports \& Outdoors, College of Health Industry, Eulji University, 553 Sanseong-daero, Sujeong-gu, Seongnam 13135, Korea Tel: +82-31-740-7130, Fax: +82-31-740-7363, E-mail: khsa2004@naver.com Received: August 27, 2018 / Accepted: September 16, 2018
This is an Open Access article distributed under the terms of the Creative Commons Attribution Non-Commercial License (http://creativecommons.org/licenses/by-nc/4.0/) which permits unrestricted non-commercial use, distribution, and reproduction in any medium, provided the original work is properly cited. 
the basic physical strengths like the muscular strength, the muscular endurance, the flexibility, the quick reaction ability, and the agility are important, for this, the plyometric training (Váczi et al., 2013), which gives the help to the muscular strength exercises, the quick reaction ability, and the agility, has been emphatically carried out. Because, among these, the content of the plyometric exercise is in the jump method, and because, in the situation of landing after the leap, the loading capacity of the weight does not get delivered to the joints of the nether extremities, it can cause a lot of the injuries to the musculoskeletal system, including the ligaments, the tendons, etc. (Spurrs et al., 2003). As a result, the busy test-takers must prepare for the practical examination by setting up a separate time other than the academic studies. Because, if they are injured during an exercise, it can cause the trouble to the preparation for the college entrance examination, it acts as a considerable feeling of the burden to the test-takers (Maffiuletti et al., 2013). The whole-body vibration exercise is a new form of exercise that draws the reaction and the adaptation of the neuromuscular system by giving the stimulations to the tendons or the muscles through the diverse frequencies of the vibrations and the strengths above the foothold where there are the vibrations (Cardinale and Pope, 2003). Cochrane and Stannard (2005) reported a significant improvement of the counter-movement jump and the flexibility. But, the actual circumstance was that there had been nearly no researches with the test-takers for the 10 biggest physical education colleges as the subjects. As a result, in this research, it is intended to take a look at what effects of the promotion of the health and the promotion of the physical strength on regarding the agility, the flexibility, and the quick reaction ability in the physical education college.

\section{MATERIALS AND METHODS}

\section{Subjects}

The subjects of this research had been the over 30 test-takers who had been preparing for the practical test together with the Korean college admission test at the G-physical education-affiliated organization for preparing for the college entrance examination, which is located in the Gangnam-gu District of Seoul. And, by randomly selecting by 10 persons each time, they were divided into the three groups. These groups were the group of the practical program for preparing for the college entrance examination regarding whom the whole-body vibration exercise had been carried out at the same time (VPE group), the group of the practical program for the preparation for the college entrance examination (PE
Table 1. The characteristics of the subjects

\begin{tabular}{lrrcc}
\hline Variable & \multicolumn{1}{c}{ VPE } & \multicolumn{1}{c}{ PE } & C & $t$ \\
\hline Age $(\mathrm{yr})$ & $19.00 \pm 0.00$ & $19.00 \pm 0.00$ & $19.00 \pm 0.00$ & \\
Height $(\mathrm{cm})$ & $175.95 \pm 7.43$ & $177.95 \pm 6.99$ & $176.45 \pm 4.43$ & 0.263 \\
Weight $(\mathrm{kg})$ & $70.38 \pm 6.48$ & $73.45 \pm 6.85$ & $71.01 \pm 10.04$ & 0.416 \\
BMl $\left(\mathrm{kg} / \mathrm{m}^{2}\right)$ & $22.73 \pm 1.77$ & $23.17 \pm 1.31$ & $22.74 \pm 2.42$ & 0.177 \\
\hline
\end{tabular}

Values are presented as the mean \pm standard deviation.

VPE, vibration with practical exercise program group; $\mathrm{PE}$, practical exercise program group; $\mathrm{C}$, control group; $\mathrm{BMI}$, the body mass index.

Group), and the control group (C Group). The subjects had been the students who had participated in the practical classes program for 3 months or longer. And the students who voluntarily had their own written consent and received the written consents by both of the protectors were selected. Also, the test-takers who had participated in a different exercise program other than the exercise program for the preparation for the practical test of the G-organization preparing for the college entrance examination and who had no experiences as an athlete were selected as the test-takers, and the persons who had the muscular skeletal diseases were excluded. And, because, in a prior test regarding the special, physical characteristics of the groups, no statistically significant difference was shown, the homogeneity was confirmed. The details regarding the special, physical characteristics and the homogeneity of the subjects of the research are the following (Table 1).

\section{Procedures}

Regarding the prior examination, in order to find out the special, general characteristics of the subjects, the body composition test was carried out. And, in order to find out the basic, physical strength, the agility, the quick reaction ability, and the flexibility tests had been carried out. After the prior examination, the subjects were randomly divided into the VPE group, the PE group, and the $\mathrm{C}$ group with 10 persons each, and the exercise program had been carried out. And, after 4 weeks, the examination that was the same as the prior examination had been carried out with the same subjects.

\section{The method of measuring the agility}

Side step

Centered on the subject, the equipment for the side step (KL Sports Industry, Seoul, Korea) was installed at the right and left distances of $120 \mathrm{~cm}$, and the measurement took place. After drawing the three lines within $1.2 \mathrm{~m}$, based on the center line, the subject stands by spreading the feet. Together with the measurement signals, centered on the center line, the subject was made to 
pass in the order of the right line, the left line, and, next, the center line. And only the case in which the whole foot crossed, it was recognized as a number of the times. The measurement took place by setting up the number of the times within $20 \mathrm{sec}$ as one time.

\section{The method of measuring the quick reaction ability}

The standing long jump

After installing the equipment for the standing long jump (KL Sports Industry), by jumping, by jumping to the front as far as possible, if the both feet touch the stepping stone, the hindmost part of the foot was recognized as a record. After measuring a total of 2 times, the higher record was made into the record of the person concerned.

\section{The standing high jump}

Regarding the equipment for the standing high jump (KL Sports Industry), by using the rebounding of the body at the place, after jumping vertically, when the two feet land above the stepping stone, the sensor calculates the duration of the flight with the height, and it gets recorded automatically. After making the subjects jump 2 times, the higher record was made into the record of the person concerned.

\section{The method of measuring the flexibility}

The sitting trunk flexion

At the sitting trunk flexion equipment (KL Sports Industry), in the condition of having straightened the two arms and the two legs of the subject, after having the subject sit down opposite the measurement device, after making the both soles of the feet touch the wide side of the measurement device, by folding the hands, by having the torso bend to the front side, the subject was made to push out the upper part of the measurement device with the finger tips. The distance of having pushed out until the end was recorded. And, after measuring a total of 2 times, the higher record was made into the record of the person concerned.

\section{Trunk forward flexion}

At the trunk forward flexion equipment (KL Sports Industry), in the condition in which the arms and the legs of the subject were straightened, after making the subject climb above the measurement device and stand erect, the both hands were folded, by bending the torso to the lower side, the subject was made to push the upper part of the measurement device with the fingertips. The distance of having pushed out until the end was recorded. And, after measuring a total of 2 times, the higher record was made into the record of the person concerned.

\section{The whole-body vibration exercise health promotion program}

After the preparatory exercises prior to the execution of the practical program for preparing for the college entrance examination, the VPE group had carried out the whole-body vibration exercise health promotion program. Based on the researches by $\mathrm{Co}$ chrane et al. (2004), beginning with the number of the vibrations at $26 \mathrm{~Hz}$, it had been increased gradually by $2 \mathrm{~Hz}$ per 1 week. And, regarding the intensity of the exercise, the application was made with the rating of perceived exertion of 13-15. Regarding the postures when vibration exercising, based on the research by Cochrane et al. (2004), they were designed with the 5 kinds, including the standing upright, squatting at a knee angle of $90^{\circ}$, lunge at knee angle of $90^{\circ}$, single right leg standing at a knee angle of $90^{\circ}$, and single left leg standing at a knee angle of $90^{\circ}$. And the whole-body vibration exercise had been applied for $3 \mathrm{~min}$ each for each posture. And, regarding the resting time of each exercise, it had been proceeded with for $40 \mathrm{sec}$ in the 3 sets.

\section{The practical program for preparing for the college entrance examination}

The preparation exercise before the execution of a practical program in preparation for the physical education-affiliated college entrance examination and the cooling down after the execution had been proceeded with the 10-min stretching. Regarding the time period of the exercise, the exercise had been carried out for

Table 2. The practical program for preparing for the college entrance examination

\begin{tabular}{|c|c|c|c|}
\hline Variable & Program & Frequency & Intensity \\
\hline Warm-up & Stretching & & RPE 11-13 \\
\hline \multirow[t]{4}{*}{ Strengthening training } & Squat & 8-12 rep/3 sets & 1RM 60\%-80\% \\
\hline & Calf-raise & & \\
\hline & Power-clean & & \\
\hline & V-sit up & & \\
\hline \multirow[t]{4}{*}{ Plyometric training } & Cone jump & 12 rep/3 sets & RPE 13-15 \\
\hline & Squat jump & & \\
\hline & Split jump & & \\
\hline & Box jump & & \\
\hline Round running (10 m/20 m) & & 5 rep & \\
\hline PNF stretching & & 3 rep & \\
\hline Cool-down & Stretching & & RPE 11-13 \\
\hline
\end{tabular}

RPE, rating of perceived exertion; PNF, proprioceptive neuromuscular facilitation; $1 \mathrm{RM}$, one-repetition maximum. 
60 min each time, 3 times a week, with a total of 4 weeks. The practical program is as in Table 2.

\section{Data analysis}

Regarding all of the data that were obtained in this research, the average $(\mathrm{M})$ and the standard deviation were calculated by using the statistical program of IBM SPSS Statistics ver. 24.0 (IBM Co., Armonk, NY, USA). Regarding the difference between the prior and afterwards variables according to the method of the exercise and the time of the measurement, the one-way analysis of variance (ANOVA) was carried out. And, in case the significance is recognized, the afterwards verification of Duncan had been carried out. And all of the statistical significance levels ( $a$ 's) were set up as being 0.05 or lower.

\section{RESULTS}

In the prior examinations of the variables between the groups, no statistically significant difference was shown, the homogeneity was confirmed (Table 3).

\section{The changes of the side step before and after an exercise}

As presented in Table 4, as a result of the one-way ANOVA of the side step, in the afterwards examination, the significant differences between the groups were shown $(F=13.546, P<0.001)$. As a result of carrying out the Duncan afterwards verification in order to take a look at the differences between the groups, although there was no difference between the VPE group and the PE group, between the VPE, PE, and $\mathrm{C}$ groups, the significant differences were shown. Or, in other words, although, in the afterwards test,

Table 3. The examination of the homogeneity of the variables between the groups

\begin{tabular}{llccc}
\hline Variable & \multicolumn{1}{c}{ VPE } & PE & $C$ & $F$ \\
\hline Side step (No. of times/20 sec) & $46.60 \pm 4.27$ & $46.10 \pm 4.79$ & $43.90 \pm 4.56$ & 0.998 \\
Standing long jump (cm/2 times) & $43.90 \pm 13.22$ & $257.40 \pm 15.23$ & $254.50 \pm 19.05$ & 0.166 \\
Standing high jump (cm/2 times) & $51.00 \pm 7.20$ & $53.80 \pm 4.76$ & $52.20 \pm 7.69$ & 0.444 \\
Sitting trunk flexion (cm/2 times) & $15.97 \pm 6.27$ & $17.32 \pm 5.70$ & $18.33 \pm 5.35$ & 0.419 \\
Trunk forward flexion (cm/2 times) & $13.35 \pm 6.55$ & $14.99 \pm 5.76$ & $15.36 \pm 5.58$ & 0.321 \\
\hline
\end{tabular}

Values are presented as the mean \pm standard deviation.

VPE, vibration with practical exercise program group; $\mathrm{PE}$, practical exercise program group; $\mathrm{C}$, control group.

Table 4. The changes of the quick reaction ability, the agility, and the flexibility before and after the exercise between the groups

\begin{tabular}{|c|c|c|c|c|c|c|}
\hline \multirow{2}{*}{ Variable } & \multirow{2}{*}{ Group } & \multicolumn{2}{|c|}{ Pretest $(n=10)$} & \multicolumn{3}{|c|}{ Posttest $(n=10)$} \\
\hline & & Mean \pm SD & $F$ & Mean \pm SD & $F$ & Posthoc \\
\hline \multirow[t]{3}{*}{ Side step (time/20 sec) } & VPE $^{a}$ & $46.60 \pm 4.27$ & 0.998 & $51.50 \pm 2.01$ & $13.546^{* * *}$ & $a, b>c$ \\
\hline & $P E^{b}$ & $46.10 \pm 4.79$ & & $49.60 \pm 3.13$ & & \\
\hline & $\mathrm{C}^{\mathrm{c}}$ & $43.90 \pm 4.56$ & & $43.90 \pm 4.56$ & & \\
\hline \multirow[t]{3}{*}{ Standing long jump (cm/2 times) } & VPE & $253.40 \pm 13.22$ & 0.166 & $263.80 \pm 8.85$ & 2.439 & \\
\hline & PE & $257.40 \pm 15.23$ & & $264.60 \pm 9.74$ & & \\
\hline & C & $254.50 \pm 19.05$ & & $253.80 \pm 16.50$ & & \\
\hline \multirow[t]{3}{*}{ Standing high jump (cm/2 times) } & $\mathrm{VPE}^{\mathrm{a}}$ & $51.00 \pm 7.20$ & 0.444 & $55.90 \pm 4.01$ & $4.061^{*}$ & $b>c$ \\
\hline & $P E^{b}$ & $53.80 \pm 4.76$ & & $57.40 \pm 2.88$ & & \\
\hline & $\mathrm{C}^{\mathrm{c}}$ & $52.20 \pm 7.69$ & & $52.10 \pm 5.55$ & & \\
\hline \multirow[t]{3}{*}{ Sitting trunk flexion (cm/2 times) } & VPE $^{a}$ & $15.97 \pm 6.27$ & 0.419 & $23.62 \pm 2.22$ & $4.451^{*}$ & $a, b>c$ \\
\hline & $P E^{b}$ & $17.32 \pm 5.70$ & & $22.45 \pm 3.45$ & & \\
\hline & $\mathrm{C}^{\mathrm{c}}$ & $18.33 \pm 5.35$ & & $18.66 \pm 5.33$ & & \\
\hline \multirow[t]{3}{*}{ Trunk forward flexion (cm/2 times) } & VPE & $13.35 \pm 6.55$ & 0.321 & $20.06 \pm 4.03$ & 3.033 & \\
\hline & PE & $14.99 \pm 5.76$ & & $19.84 \pm 4.51$ & & \\
\hline & C & $15.36 \pm 5.58$ & & $15.59 \pm 5.12$ & & \\
\hline
\end{tabular}

Values are presented as the mean \pm standard deviation.

VPE, vibration with practical exercise program group; $P E$, practical exercise program group; $C$, control group.

${ }^{*} P<0.05$. ${ }^{* *} P<0.001$. 
compared to the prior test, there had been the increases of the VPE group and the PE group at 4.9 times/20 sec, and 3.5 times/ 20 sec, respectively, regarding the $C$ group, because there were no changes of the side step, the difference between the groups was shown.

\section{The changes of the standing long jump before and after an exercise}

As presented in Table 4, as a result of the one-way ANOVA of the standing long jump, in the afterwards examination, no significant difference between the groups was shown $(F=2.439$, $P>0.05$ ). If we take a look at the average value of the standing long jump, in the afterwards examination, compared to the prior examination, the VPE group and the PE group had the increases of $12.5 \mathrm{~cm} / 2$ times and $7.2 \mathrm{~cm} / 2$ times, respectively. And the $C$ group had been decreased by $0.7 \mathrm{~cm} / 2$ times.

\section{The changes of the standing high jump before and after an exercise}

As presented in Table 4, as a result of the one-way ANOVA of the standing high jump, in the afterwards examination, the significant differences between the groups were shown $(P<0.05)$. Although, as a result of carrying out Duncan's afterwards verification in order to take a look at the differences between the groups, there were no differences between the VPE group, the C group, the VPE group, and the PE group, and, between the PE group and the $\mathrm{C}$ group, a significant difference was shown. Or, in other words, although, in the afterwards test, compared to the prior test, regarding the VPE group and the PE group, there had been the increases of $4.90 \mathrm{~cm} / 2$ times $\mathrm{m}$ and $3.70 \mathrm{~cm} / 2$ times, respectively, because the $\mathrm{C}$ group had nearly no changes $(0.1 \mathrm{~cm} /$ 2 times reduction), the difference between the groups was shown.

\section{The changes of the sitting trunk flexion before and after an exercise}

As presented in Tables 3 and 4, as a result of the one-way ANOVA of the sitting trunk flexion, in the afterwards examination, the significant difference between the groups was shown $(P<0.05)$. Although, as a result of having carried out the Duncan's post verification in order to take a look at the differences between the groups, there were no differences between the VPE group and the PE group, between the VPE group, the PE group, and the $\mathrm{C}$ group, the significant differences were shown. Or, in other words, in the afterwards examination, compared to the prior examination, although the VPE group and the PE group had the increases of $7.65 \mathrm{~cm} / 2$ times $\mathrm{m}$ and $5.13 \mathrm{~cm} / 2$ times, respectively, because the $C$ group had nearly no changes (increase by $0.33 \mathrm{~cm} / 2$ times), the difference between the groups was shown.

\section{The changes of the trunk forward flexion before and after an exercise}

As presented in Table 4, in the afterwards examination of the results of the one-way ANOVA of the trunk forward flexion, no significant difference was shown between the groups $(P>0.05)$. Or, in other words, in the afterwards examination, compared to the prior examination, regarding the average values of the VPE group and the PE group, there had been the increases of $6.71 \mathrm{~cm} /$ 2 times and $4.85 \mathrm{~cm} / 2$ times, respectively. And, although, regarding the $\mathrm{C}$ group, there had been nearly no change (the increase of $0.23 \mathrm{~cm} / 2$ times), statistically, no significant difference was shown.

\section{DISCUSSION}

In around the year 2000, with the researches related to the improvement of the exercise function of the whole-body vibrations, which had been supplied at a rapid speed by being centered on Europe, being continuously reported, they have been used usefully in the fields of rehabilitation and sports in Korea, too. Applying the program for the promotion of the health through the whole-body vibration exercise, which proves to be helpful to the improvement of the basic physical strength by safely carrying it out within a short time, it had been taken a look into what effects it has on the quick reaction ability, the agility, and the flexibility of the test-takers who had been preparing for the practical examination for the admission into the school in a physical education-affiliated department (Rittweger et al., 2002). But, with the actual circumstance being that there had been nearly no precedent researches, there is the limitation that the results of this research and the results of the previous researches cannot be sufficiently compared.

In order to see the effect of the agility, on a $120-\mathrm{cm}$ line, the side step was measured for $20 \mathrm{sec}$ for 2 times. As a result of the research, the significant difference between the groups was shown $(P<0.001)$, and, regarding the average value, too, that of the VPE group was the highest compared to the other groups. Cormie et al. (2006) reported the significant enhancement of the vertical jump height and the agility after the application of the wholebody vibration exercise for $30 \mathrm{sec}$ compared to the $\mathrm{C}$ group. Also, as a result of maintaining the 5 postures for $40 \mathrm{sec}$ each at the 
strength of $26 \mathrm{~Hz}$. Cochrane et al. (2004) reported the significant improvement of the agility and has been supporting this research. As a result, in this research, as the related variables of the quick reaction ability, the standing long jump and the standing high jump had been applied and measured. Although, as a result of this research, the standing long jump did not show any significant difference between the groups $(P>0.05)$, if we take a look the average values, that of the VPE group had increased the highest compared to the other groups. But, the standing high jump showed the significant differences between the groups $(P<0.05)$, and the VPE group showed the highest average value. Cormie et al. (2006) reported the significant improvement of the vertical jump height after the whole-body vibration exercise of $30 \mathrm{sec}$ compared to the placebo group, the results coincided. Torvinen et al. (2002) reported the increase rate of the ability to jump vertically of $10.2 \%$ after 2 months and $8.5 \%$ after 4 months. And, by saying that there is the high correlation between the whole-body vibration exercise and the quick reaction ability, they have been supporting the results of this research. But, the researches on the correlation between the whole-body vibration exercise and the standing long jump are nonexistent, and there is the limitation that it cannot be comparatively analyzed with the precedent researches. In this research, by using the sitting trunk flexion and the trunk forward flexion, which are frequently used for the flexibility test of the program for promoting the health through the whole-body vibration exercise, the effects on the flexibility had been taken a look at.

Although, regarding the sitting trunk flexion, the significant differences between the groups were shown $(P<0.05)$, regarding the trunk forward flexion, no significant difference was shown $(P>0.05)$. But, regarding both variables, the VPE group showed the highest average value. Such results mean that the program for the promotion of the health through the whole-body vibration exercise has the effect on the flexibility as an auxiliary means. With the healthy adults as the subjects and after applying the whole-body vibration exercise at $25 \mathrm{~Hz}$ for $6 \mathrm{~min}$, Gerodimos et al. (2010) reported the significant improvement of the flexibility. If we take a look at the physiological mechanism of the wholebody vibration exercise, there is the relationship with the stretch reflex using the high stretching loads (Issurin and Tenenbaum, 1999). Application of the whole-body vibration exercise showed the effects on the quick reaction ability, the agility, and the flexibility was because the cocontraction of the synergist muscles had been increased even more by invigorating the nervous system even more together with the simultaneous activation of the motor nerves. Especially, the fact that the ability to jump in the standing high jump had been increased can be explained as the appearance of the vibration effect to be even bigger because the degree of the sensitivity of the muscle spindles had increased according to the increase of the length of the muscles. (Burke et al., 1976).

As a result, this research proved that, as an auxiliary means for the practice program for the college entrance examination for a physical education-affiliated department, the program for promoting the health of the whole-body vibration exercise has the effects on the improvements of the agility, the quick reaction ability, and the flexibility. But, as the number of the subjects had been small, as it had been carried out at a restricted place, and as there had been the limitations which had been difficult to interpret, based on the results of this research, the researches with the diverse subjects and the researches which apply the program for the whole-body vibration exercise, which is subdivided, must take place vigorously. Regarding the test-takers who had been preparing for the practical test for the college entrance examination to enter a physical education-affiliated department, by using the program for the promotion of the health through the whole-body vibration exercise as an auxiliary means, this research had comparatively analyzed what effects there are on the agility, the quick reaction ability, and the flexibility. If I were to put together the results of this research, as the results of the research, in the side step, the standing high jump, and the sitting trunk flexion, the significant differences between the groups were shown. And in the standing long jump and the trunk forward flexion, no significant difference was shown. But, the VPE group showed the highest average value compared to the other groups. Such results mean that the program for the promotion of the health through the whole-body vibration exercise becomes of a help to the auxiliary means for the basic, physical strengths of the test-takers who have been preparing for the practical test of the college entrance examination. But, because the number of the students had been small and because it had been carried out in a restricted area, it is difficult to interpret. As a result, based on the results of this research, for the diverse subjects, by developing a systematic and subdivided whole-body vibration exercise program, it must become of a help to the basic, physical strengths of the test-takers.

\section{CONFLICT OF INTEREST}

No potential conflict of interest relevant to this article was reported. 


\section{REFERENCES}

Burke D, Hagbarth KE, Löfstedt L, Wallin BG. The responses of human muscle spindle endings to vibration during isometric contraction. J Physiol 1976;261:695-711.

Cardinale M, Pope MH. The effects of whole body vibration on humans: dangerous or advantageous? Acta Physiol Hung 2003;90:195-206.

Cochrane DJ, Legg SJ, Hooker MJ. The short-term effect of whole-body vibration training on vertical jump, sprint, and agility performance. J Strength Cond Res 2004;18:828-832.

Cochrane DJ, Stannard SR. Acute whole body vibration training increases vertical jump and flexibility performance in elite female field hockey players. Br J Sports Med 2005;39:860-865.

Cormie P, Deane RS, Triplett NT, McBride JM. Acute effects of wholebody vibration on muscle activity, strength, and power. J Strength Cond Res 2006;20:257-261.

Gerodimos V, Zafeiridis A, Karatrantou K, Vasilopoulou T, Chanou K, Pispirikou E. The acute effects of different whole-body vibration amplitudes and frequencies on flexibility and vertical jumping performance. J Sci Med Sport 2010;13:438-443.
Issurin VB, Tenenbaum G. Acute and residual effects of vibratory stimulation on explosive strength in elite and amateur athletes. J Sports Sci 1999;17:177-182.

Maffiuletti NA, Saugy J, Cardinale M, Micallef JP, Place N. Neuromuscular fatigue induced by whole-body vibration exercise. Eur J Appl Physiol 2013;113:1625-1634.

Rittweger J, Ehrig J, Just K, Mutschelknauss M, Kirsch KA, Felsenberg D. Oxygen uptake in whole-body vibration exercise: influence of vibration frequency, amplitude, and external load. Int J Sports Med 2002; 23:428-432.

Spurrs RW, Murphy AJ, Watsford ML. The effect of plyometric training on distance running performance. Eur J Appl Physiol 2003;89:1-7.

Torvinen S, Kannu P, Sievänen H, Järvinen TA, Pasanen M, Kontulainen S, Järvinen TL, Järvinen M, Oja P, Vuori I. Effect of a vibration exposure on muscular performance and body balance. Randomized crossover study. Clin Physiol Funct Imaging 2002;22:145-152.

Váczi M, Tollár J, Meszler B, Juhász I, Karsai I. Short-term high intensity plyometric training program improves strength, power and agility in male soccer players. J Hum Kinet 2013;36:17-26. 